\title{
PATTERN AND BURDEN OF ANTIMICROBIAL RESISTANCE AMONG CAUSATIVE ORGANISMS OF SPONTANEOUS BACTERIAL PERITONITIS.
}

\author{
DR. MOHSIN IKRAM, MBBS \\ Department of Medicine, Akhtar Saeed Trust Hospital, Lahore, Pakistan. \\ DR. UROOJ RAMZAN, MBBS \\ Department of Medicine, Nishtar Medical University, Multan, Pakistan. \\ DR. KUBRA AFAQ, BDS \\ Nishtar Institute of Dentistry, Multan, Pakistan.
}

\begin{abstract}
Background; Spontaneous bacterial peritonitis is a common bacterial infection in patients with cirrhosis and ascities with in-hospital mortality rates ranging from 20 to $30 \%$. Early diagnosis and a prompt antibiotic therapy have considerably decreased the mortality rate and this study was done to determine drug resistance pattern among causative organisms of SBP. Material and Methods; All the cases $(n=183)$ of Cirrhosis of liver with ascities, fulfilling inclusion criteria were recruited from Department of Medicine Akhtar Saeed Trust Hospital Lahore and Nishtar Hospital, Multan. All selected patients were subjected to ascitic fluid tap, under aseptic measures by inserting a needle of 22 / 18 gauge in the left flank of abdomen. Ten $\mathrm{ml}$ of ascitic fluid was aspirated in a heparinised disposable syringe; which was immediately inoculated into blood culture bottle at bedside and send for bacterial culture and causative organisms was tested for their antibiotic drug resistance pattern. Data was entered and analyzed by computer program SPSS-18. Results; Of these 183 study cases, 103 (56.3\%) were male patients while $80(43.7 \%)$ were female patients. Mean age of our study cases was $51.73 \pm 9.28$ years. Previous history of use of antibiotics before 72 hours was noted in 103 (56.3\%), anti - HCV was positive in 103 (56.3\%) while HBs Ag was positive in $13.7 \%$ of our study cases. Among these study cases, E.coli was noted in 135 (73.8\%), Staph. Aureus in $17.5 \%$ and Klebsiella was noted in $8.7 \%$. Chloramphenicol was resistant in 24 (13.1\%), ampicillin was resistant in $143(78.1 \%$ ), co - trimoxazole in $61.2 \%$, ciprofloxacin in 55.7\%, Ofloxacin in 56.3\%, Cefotaxime was resistant in $78.1 \%$ and amoxicillin was resistant in $74.9 \%$. Conclusion; High degree of drug resistance was observed among these strains in our study which points towards well directed efforts of our health policy makers to adopt certain guidelines regarding use of these drugs in our population. Our study results have indicated that E.coli was major causative organisms among patients with spontaneous bacterial peritonitis having cirrhosis of liver followed by staphylococcus aureus and klebsiella.
\end{abstract}

Keywords; Cirrhosis, spontaneous bacterial peritonitis, E. coli.

DOI: $10.7176 / \mathrm{JMPB} / 67-07$

Publication date:August $31^{\text {st }} 2020$

\section{Introduction;}

Spontaneous bacterial peritonitis (SBP) is one of the leading causes of morbidity and mortality in patients with cirrhosis. Spontaneous bacterial peritonitis (SBP) is a common bacterial infection in patients with cirrhosis and ascities, occurring in 10 to $30 \%$ of patients, with in-hospital mortality rates ranging from 20 to $30 \%$. ${ }^{1-3}$ Early diagnosis and a prompt antibiotic therapy have considerably decreased the mortality rate associated with an episode of SBP from $80 \%$ to approximately $20-30 \%$ in the last decade ${ }^{4}$. It is secondary to impaired humoral and cellular immune responses that result in indirect intestinal bacterial translocation into the ascitic fluid..$^{5,6}$

It is defined as bacterial infection of the ascitic fluid in the absence of an apparent intra abdominal source of infection. The incidence of spontaneous bacterial peritonitis in hospitalized patients with cirrhosis varies from 7$23 \%$ in the West. It is around 33\% in Pakistan ${ }^{7}$. Translocation of bacteria (mostly gram negative) from the intestinal lumen due to decreased phagocytic activity of macrophages and increased intestinal permeability in cirrhotic patients is an important step in the development of spontaneous bacterial peritonitis 7,8 . 
A study conducted in Khyber teaching hospital, Peshawar reported E.coli in $58.13 \%$, Staphylococcus aureus in $9.30 \%$ and Klebseilla in $9.30 \%$ in cirrhotic patients with SBP ${ }^{9}$. Another study documented chloramphenicol resistant in $6.2 \%$, ciprofloxacin in 45.4\%, Cotrimoxazol in 62\%, Ampicillin in 66.6\%, Ofloxacin 42.9\%, Cefotaxime in $77.3 \%$, Amoxycillin in $64.7 \%$ of bacterial isolates of SBP patients with liver cirrhosis. ${ }^{10}$

Spontaneous bacterial peritonitis is also associated with a poor long-term with one year mortality of 50 to $70 \%$. Given that timely and appropriate antibiotic treatment can improve the clinical outcome. Rapid and accurate diagnostic methods for early detection of bacterial infection responsible for SBP and identification of the causative organisms involved could be particularly useful in acute care settings. Recent attention drawn to the changing microbial and resistance patterns attributed to the increasing use of antibiotic prophylaxis and invasive procedures in such patients further underscores the importance of identifying the causative pathogen to ensure adequate antibiotic coverage ${ }^{11}$. Only a few studies have documented microbial spectrum/causative organisms of SBP in cirrhotic patients but all these studies have been done with small sample size. Only one recent study from Karachi ${ }^{12}$ have documented culture sensitivity of these causative organisms. Moreover frequency of predominant causative organisms such as E. coli has been reported to be $18 \%{ }^{11}$ to $65 \%^{12}$, showing great variation.

\section{Material and Methods;}

All the cases $(n=183)$ of Cirrhosis of liver with ascities, fulfilling inclusion criteria were recruited from Department of Medicine Akhtar Saeed Trust Hospital Lahore and Nishtar Hospital Multan, Pakistan. Patients with liver cirrhosis aged 40 - 70 years, having disease duration more than 6 months of either sex presenting with SBP having duration less than one week were included in our study. Patients with Tubercular peritonitis and congestive heart failure, those taking antibiotics within 72 hours, having diabetes, hypertension and malignancies were excluded from our study. All selected patients were subjected to ascitic fluid tap, under aseptic measures by inserting a needle of 22 / 18 gauge in the left flank of abdomen. Ten ml of ascitic fluid was aspirated in a heparinised disposable syringe; which was immediately inoculated into blood culture bottle at bedside and send for bacterial culture and causative organisms was tested for their antibiotic drug resistance pattern. Data was entered and analyzed by computer program SPSS-18.

\section{Results;}

Our study included a total of 183 study cases in patients having liver cirrhosis with spontaneous bacterial peritonitis (SBP), who met inclusion criteria of our study. Of these 183 study cases, 103 (56.3\%) were male patients while 80 $(43.7 \%)$ were female patients. Mean age of our study cases was $51.73 \pm 9.28$ years (with minimum age of our study cases was 41 years while maximum age was 70 years). Mean age of the male patients was noted to be 53.97 \pm 10.25 years while that of female patients was noted to be $48.84 \pm 6.91$ years $(\mathrm{p}=0.000)$. Our study results have documented that majority of our study cases i.e. $112(61.2 \%)$ were aged $40-55$ years of age. Mean duration of disease (liver cirrhosis) was $26.43 \pm 12.32$ months while mean duration of SBP was $4.51 \pm 1.21$ days.

Previous history of use of antibiotics before 72 hours was noted in 103 (56.3\%), anti - HCV was positive in 103 (56.3\%) while $\mathrm{HBs} \mathrm{Ag}$ was positive in $13.7 \%$ of our study cases. History of alcohol consumption was noted in 31 $(16.9 \%)$ of our study cases. Among these study cases, E.coli was noted in 135 (73.8\%), Staph. Aureus in $17.5 \%$ and Klebsiella was noted in 8.7\%. Chloramphenicol was resistant in 24 (13.1\%), ampicillin was resistant in 143 $(78.1 \%)$, co - trimoxazole in $61.2 \%$, ciprofloxacin in $55.7 \%$, Ofloxacin in $56.3 \%$, Cefotaxime was resistant in $78.1 \%$ and amoxicillin was resistant in $74.9 \%$.

\section{Discussion;}

Spontaneous bacterial peritonitis (SBP) is a common and frequently fatal bacterial infection of ascites occurring in patients with cirrhosis who have diverse symptomatology ${ }^{13-15}$. Several subgroups of cirrhotic patients have been shown to be predisposed to develop spontaneous bacterial peritonitis, including cases with gastrointestinal hemorrhage, patients with high serum bilirubin and low ascitic fluid protein concentration $(<1 \mathrm{~g} / \mathrm{dl})$, and patients who had recovered from an episode of spontaneous bacterial peritonitis. Since spontaneous bacterial peritonitis is 
associated with a relatively high in-hospital mortality rate (20-40\%), prophylactic measures to prevent this infection are required ${ }^{16}$.

Our study included a total of 183 study cases in patients having liver cirrhosis with spontaneous bacterial peritonitis (SBP), who met inclusion criteria of our study. Of these 183 study cases, 103 (56.3\%) were male patients while 80 $(43.7 \%)$ were female patients. A study conducted in Peshawar by Iqbal et al ${ }^{9}$ has also reported male gender preponderance with $55.88 \%$ which is similar to that of our study results. A study by Sheikhbahaie et al ${ }^{10}$ also reported male gender predominance with male: female ratio was 1.25:1 which is in compliance with our study results. Oladimeji et al ${ }^{17}$ also reported male gender predominance with $54.8 \%$ which is in compliance with our study results.

Mean age of our study cases was $51.73 \pm 9.28$ years (with minimum age of our study cases was 41 years while maximum age was 70 years). Mean age of the male patients was noted to be $53.97 \pm 10.25$ years while that of female patients was noted to be $48.84 \pm 6.91$ years $(\mathrm{p}=0.000)$. Our study results have documented that majority of our study cases i.e. $112(61.2 \%)$ were aged $40-55$ years of age. A study conducted in Peshawar by Iqbal et al 9 has also reported similar results. A study by Sheikhbahaie et al ${ }^{10}$ documented mean age of the patients with SBP was $51 \pm 9$ years which is similar to that of our study results. Bibi et al ${ }^{12}$ from Karachi reported $46.45 \pm 13.71$ years mean age which is in compliance with that of our study results. Oladimeji et al ${ }^{17}$ also reported62 \pm 9 years mean age of SBP patients having liver cirrhosis which is close to our findings.

Previous history of use of antibiotics before 72 hours was noted in 103 (56.3\%), anti - HCV was positive in 103 $(56.3 \%)$ while $\mathrm{HBs} \mathrm{Ag}$ was positive in $13.7 \%$ of our study cases. History of alcohol consumption was noted in 31 $(16.9 \%)$ of our study cases. Bibi et al ${ }^{12}$ from Karachi reported that anti - HCV was positive in $68.4 \%$ while HBs Ag was positive in $15.4 \%$ which is close to our findings.

Among these study cases, E.coli was noted in 135 (73.8\%), Staph. aureus in $17.5 \%$ and Klebsiella was noted in 8.7\%. A study conducted in Peshawar by Iqbal et al ${ }^{9}$ has also reported E.coli being predominant causative agent of the SBP with $58.13 \%$, staph. aureus was $9.30 \%$ and Klebsiella was $9.30 \%$. These findings are similar to that of our study results. Bibi et al ${ }^{12}$ from Karachi reported E.coli in $63.5 \%$ SBP cases having liver cirrhosis which is close to our study results. Oladimeji et al ${ }^{17}$ also reported $70 \%$ E. coli predominating among causative organisms of SBP which is close to our findings.

Chloramphenicol was resistant in 24 (13.1\%), ampicillin was resistant in 143 (78.1\%), co - trimoxazole in 61.2\%, ciprofloxacin in $55.7 \%$, Ofloxacin in $56.3 \%$, Cefotaxime was resistant in $78.1 \%$ and amoxicillin was resistant in $74.9 \%$. A study by Sheikhbahaie et al ${ }^{10}$ documented chloramphenicol resistant in $6.2 \%$, ciprofloxacin in $45.4 \%$, Cotrimoxazol in $62 \%$, Ampicillin in $66.6 \%$, Ofloxacin $42.9 \%$, Cefotaxime in $77.3 \%$, Amoxycillin in $64.7 \%$ of bacterial isolates of SBP patients with liver cirrhosis which are in compliance with that of our study results.

\section{Conclusion;}

High degree of drug resistance was observed among these strains in our study which points towards well directed efforts of our health policy makers to adopt certain guidelines regarding rationale use of these drugs in our population. Our study results have indicated that E.coli was major causative organisms among patients with spontaneous bacterial peritonitis having cirrhosis of liver followed by staphylococcus aureus and klebsiella.

\section{References}

1. Mostafa MS, El-Seidi EA, Kassem AM, Shemis MA, Saber M, Michael MN. Detection of ascitic fluid infections in patients with liver cirrhosis and ascites. Arab J Gastroenterol. 2011;12:20-4.

2. Appenrodt B, Lehmann LE, Thyssen L, Gentemann M, Rabe C, Molitor E, et al. Is detection of bacterial DNA in ascitic fluid of clinical relevance? Eur J Gastroenterol Hepatol. 2010;22(12):1487-94.

3. Barreales M, Fernandez I. Spontaneous bacterial peritonitis. Rev Esp Enferm Dig. 2011;103:255-63.

4. Terg R, Cobas S, Fassio E, Landiera G, Rios B, Vasen W, et al., "Oral ciprofloxacin after a short course of intravenous ciprofloxacin in the treatment of spontaneous bacterial peritonitis: results of a multicenter, randomized study," J Hepatol. 2000;33(4):564-9. 
5. Soriano $\mathrm{G}^{1}$, Esparcia O, Montemayor M, Guarner-Argente C, Pericas R, Torras X, et al. Bacterial DNA in the diagnosis of spontaneous bacterial peritonitis. Aliment Pharmacol Ther. 2011;33(2):275-84.

6. Rogers GB ${ }^{1}$, Russell LE, Preston PG, Marsh P, Collins JE, Saunders J, et al. Characterization of bacteria in ascites--reporting the potential of culture-independent, molecular analysis. Eur J Clin Microbiol Infect Dis. 2010;29(5):533-41.

7. Zaman A, Kareem R, Mahmood R, Hameed K, Khan EM. Frequency of microbial spectrum of spontaneous bacterial peritonitis in established cirrhosis of liver. J Ayub Med Coll Abbottabad. 2011;23(4):15-7.

8. Gill AS, Singh A, Matreja PS, Chinna RS, Mahajan R, Chhina DK. Spontaneous bacterial peritonitis in alcoholic cirrhosis: an Indian perspective. Euroasian J Hepato-Gastroenterol 2012;2(1):14-9.

9. Iqbal S, Imran N, Alam N, Rahman S. Incidence of spontaneous bacterial peritonitis in liver cirrhosis, the causative organisms and antibiotic sensitivity. J Postgrad Med Inst 2004;18(4):614-9.

10. Sheikhbahaei S, Abdollahi A, Hafezi-Nejad N, Zare E. Patterns of antimicrobial resistance in the causative organisms of spontaneous bacterial peritonitis: a single centre, six-year experience of 1981 samples. Int J Hepatol. 2014;2014:917856. doi: 10.1155/2014/917856

11. Hardick J, Won H, Jeng K, Hseih Y, Gaydos CA, Rothman RE, et al. Identification of bacterial pathogens in ascitic fluids from patients with suspected spontaneous bacterial peritonitis by use of broad-range PCR (16S PCR) coupled with high-resolution melt analysis. J Clin Microbiol. 2012;50(7):2428-32.

12. Bibi S, Ahmed W, Arif A, Khan F, Alam SE. Clinical, Laboratory and Bacterial Profile of Spontaneous Bacterial Peritonitis in Chronic Liver Disease Patients. J Coll Physicians Surg Pak. 2015;25(2):95-9.

13. Salerno F, Navickis RJ, Wilkes MM. Albumin infusion improves outcomes of patients with spontaneous bacterial peritonitis: a meta-analysis of randomized trials. Clin Gastroenterol Hepatol. 2013;11:12330.e1.

14. Musskopf MI, Fonseca FP, Gass J, de Mattos AZ, John JA, de Mello Brandão AB. Prognostic factors associated with in-hospital mortality in patients with spontaneous bacterial peritonitis. Ann Hepatol. 2012;11:915-20.

15. Mounzer R, Malik SM, Nasr J, Madani B, Devera ME, Ahmad J. Spontaneous bacterial peritonitis before liver transplantation does not affect patient survival. Clin Gastroenterol Hepatol. 2010;8:623-28.

16. Dever $\mathrm{JB}^{1}$, Sheikh MY. Review article: spontaneous bacterial peritonitis--bacteriology, diagnosis, treatment, risk factors and prevention. Aliment Pharmacol Ther. 2015 Jun;41(11):1116-31.

17. Oladimeji AA, Temi AP, Adekunle AE, Taiwo RH, Ayokunle RS. Prevalence of spontaneous bacterial peritonitis in liver cirrhosis with ascites. Pan Afr Med J. 2013;15:128. doi: 10.11604/pamj.2013.15.128.2702 